\title{
Geographical distribution of publications in the field of medical education Oktay Tutarel
}

Address: Hannover Medical School, Hannover, Germany

E-mail: otutarel@hotmail.com

Published: 30 April 2002

Received: 14 January 2002

BMC Medical Education 2002, 2:3

Accepted: 30 April 2002

This article is available from: http://www.biomedcentral.com//472-6920/2/3

(C) 2002 Tutarel; licensee BioMed Central Ltd. Verbatim copying and redistribution of this article are permitted in any medium for any purpose, provided this notice is preserved along with the article's original URL.

\begin{abstract}
Background: The geographical distribution of publications as an indicator of the research productivity of individual countries, regions or institutions has become a field of interest. We investigated the geographical distribution of contributions to the two leading journals in the field of medical education, Academic Medicine and Medical Education.
\end{abstract}

Methods: PubMed was used to search Medline. For both journals all journal articles in each year from 1995 to 2000 were included into the study. Then the affiliation was retrieved from the affiliation field of the MEDLINE format. If this was not possible, it was obtained from the paper version of the journal.

Results: Academic Medicine published contributions from 25 countries between 1995 and 2000. Authors from 50 countries contributed to Medical Education in the same period of time. Authors from the USA and Canada wrote ca. $95 \%$ off all articles in Academic Medicine, whereas authors from the UK, Australia, the USA, Canada and the Netherlands were responsible for ca. $74 \%$ of all articles in Medical Education in the investigated period of time.

Conclusions: While many countries contributed to both journals, only a few of them were responsible for the majority of all articles.

\section{Background}

The geographical distribution of publications as an indicator of the research productivity of individual countries, regions or institutions has recently become a field of interest. It has been investigated for the members of the European Union [1], the USA [2], the Gulf Cooperation Council countries [3], Colombia [4], South Korea [5] and for a Turkish medical school [6]. The research output of individual [7] and selected countries [8,9] for single specialties, as well as the contribution of individual countries to selected journals [10] has also been reviewed. To the best of our knowledge such an investigation was not carried out in the field of medical education. But would it not be important to find out which countries are the most influential concerning the future of medical education? Who are the opinion formers and who does not take part in this important discussion? One way to answer these questions is to investigate which countries contribute to the most prestigious journals in this field. Therefore a study of the geographical distribution of publications in the two leading medical education journals determined by their impact factor was carried out. The number of countries that contributed to Academic Medicine and Medical Education and the amount of their contribution was examined with the help of the Internet provider 
PubMed, the Medline-database of the National Library of Medicine [11].

\section{Methods}

\section{Medical education journals and their impact factor}

In the 1999 Journal Citation Reports-Science Edition [12] 13 journals were listed in the subject category "education, scientific disciplines". Academic Medicine had the highest impact factor with 1.472, followed by Medical Education with 0.958. All the remaining journals - not only those ones dealing with medical education, but also journals like the Journal of Biological Education - had an impact factor below 0.65. Six of the remaining eleven had an impact factor below 0.32 . The third ranked medical education periodical was Medical Teacher with an IF of 0.574 . Out of these 13 journals only Academic Medicine and Medical Education were listed in PubMed in each of the years from 1995 to 2000 .

Nineteen journals were listed in PubMed under the MeSH heading "education, medical" [13]. Five of these journals were predecessors of some of the remaining 14 journals, e.g. the British Journal of Medical Education as the predecessor of Medical Education. Only four journals were listed in PubMed throughout the whole investigated period of time. These are Academic Medicine, Comprehensive Therapy, Health Policy and Medical Education. Out of this four only Academic Medicine and Medical Education were also listed in the subject category "education, scientific disciplines" of the 1999 Journal Citation Reports-Science Edition [12].

\section{Journal selection}

Although science is a discipline that prides itself on precision, quantification, standards, and controls, there is no absolute gold standard for the quality of scientific publications [14]. Only the two leading journals with the highest impact factor in the field of medical education (category: education, scientific disciplines) [12] were investigated in this study to introduce some quality assessment. No measure of quality is perfect (or even close to it), but the citation index does provide some indication of how reliable, important, and useful investigators find the work that is published in a given journal [15]. The impact factor is not valid for the assessment of the quality of individual papers, but it is a valid tool for the quality assessment of scientific journals [16].

\section{Search methodology}

PubMed was used to search Medline in December 2001. Preview/Index was selected from the features bar. Academic Medicine or Medical Education was entered into the "Journal" field. The search included the years from 1995 to 2000, which were entered into the "Publication Date" field, respectively. Finally journal article was select- ed as "Publication Type" to exclude letters, editorials, news, etc. [17]. The search results were displayed in the MEDLINE format and the affiliation for each entry was retrieved for each journal in each year. If the affiliation of an entry could not be obtained from PubMed, it was looked up in the paper version of the journal. If more than one country was listed in the affiliation, each of them was rewarded with a count.

\section{Results}

From 1995 to 20002207 journal articles were published in Academic Medicine and 746 journal articles were published in Medical Education. The number of published articles per year increased for both journals (Fig. 1). The affiliation could not be retrieved for 35 entries (1.6\% of all articles) from Academic Medicine and for 38 entries (5.1\% of all articles) from Medical Education.

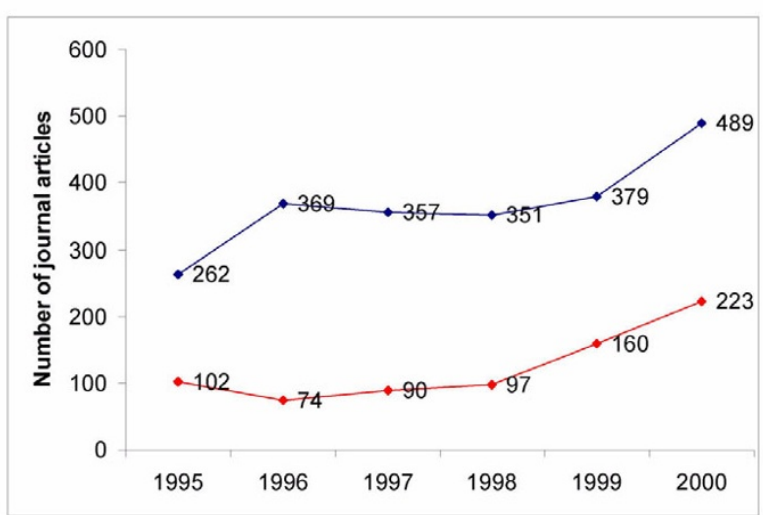

\section{Figure I}

Number of journal articles published per year in Academic Medicine and Medical Education The blue line represents Academic Medicine and the red line Medical Education.

Academic Medicine published articles from 25 different countries between 1995 and 2000, whereas Medical Education had contributions from 50 countries in the same period of time (Table 1).

Three countries contributed at least one article in each year of the investigated period of time to the journal Academic Medicine. These countries are the USA, Canada and the Netherlands.

Eight countries contributed at least one article in each of the six years to Medical Education. These countries are Australia, Canada, Hong Kong, New Zealand, Sweden, the Netherlands, the UK and the USA. 
Table I: Number of countries that contributed to each journal

\begin{tabular}{ccccccccc}
\hline & 1995 & 1996 & 1997 & 1998 & 1999 & 2000 & $1995-2000$ \\
\hline Academic Medicine & 12 & 7 & 9 & 15 & 12 & 10 & 25 \\
Medical Education & 31 & 23 & 17 & 21 & 24 & 22 & 50 \\
\hline
\end{tabular}

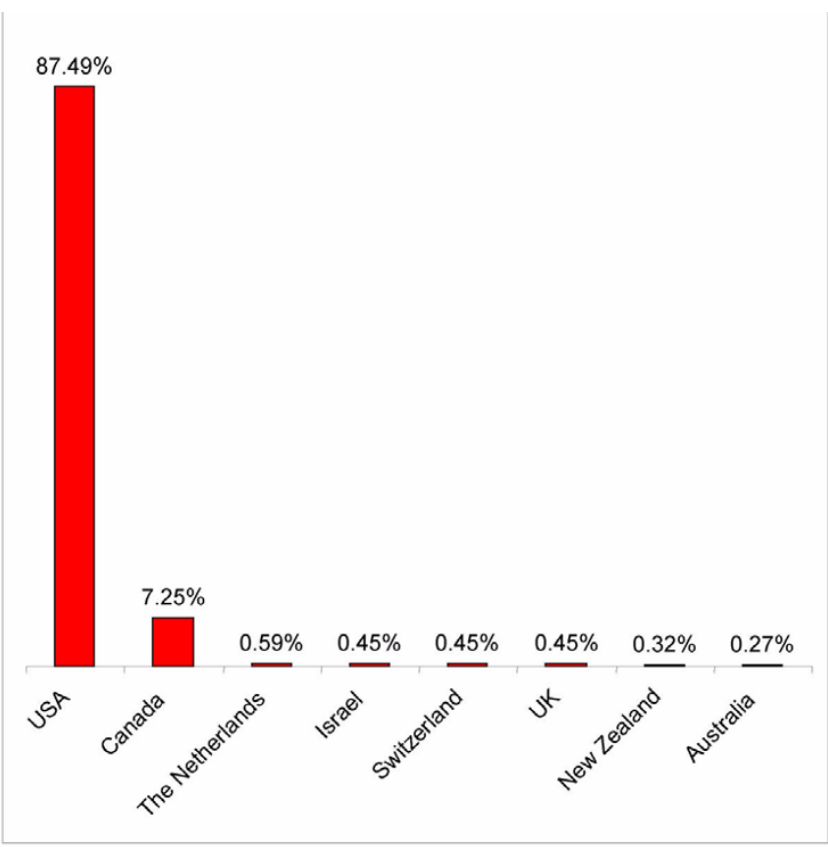

Figure 2

The eight leading countries in Academic Medicine and their share in per cent

Authors from the USA were responsible for $87.5 \%$ and their colleagues from Canada for $7.2 \%$ of all articles in Academic Medicine (Table 2, Fig. 2). In Medical Education authors from the United Kingdom, Australia, the USA, Canada and the Netherlands together contributed approximately $74 \%$ of all articles (Table 2, Fig. 3 ).

\section{Discussion}

In this investigation the geographical distribution of publications in the two leading medical education journals and the contribution of individual countries to both journals were studied. Authors from all over the world published articles in Medical Education and to a lesser extent in Academic Medicine, but both journals were dominated by authors from a few English-speaking countries with the exception of the Netherlands. Most of the articles in Academic Medicine were written by US and to a lesser extent Canadian researchers, whereas authors from the UK, Aus-

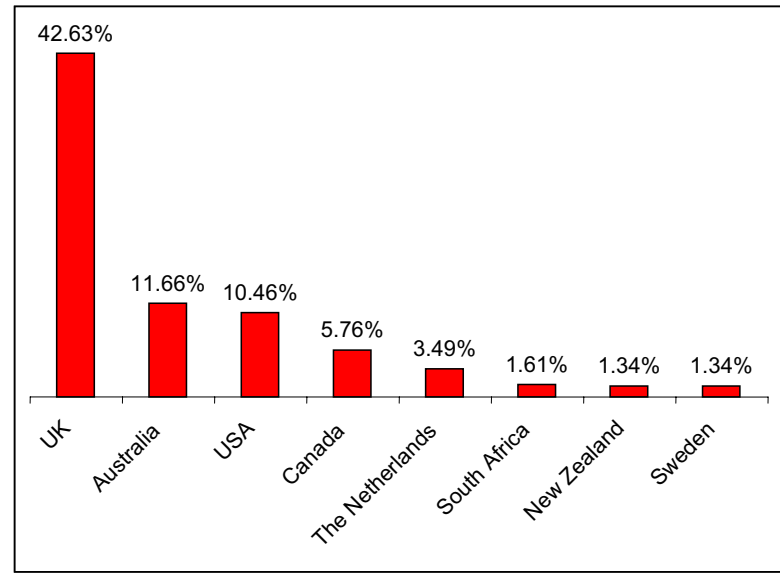

Figure 3

The eight leading countries in Medical Education and their share in per cent

tralia, Canada and the USA were the main contributors to Medical Education.

Recently Kremer et al. investigated the geographical distribution of publications in reproductive medicine [18]. They compared the number of publications in the two leading journals of this field and found that the UK was the most productive country in one journal and that the USA was the most productive country in the other as well as in both journals together. This is in accordance with our results that show the UK as the leading nation in Medical Education (42.6\% of all articles), whereas authors from the United States were the most productive contributors to Academic Medicine (87.5\%) and both journals together $(68 \%)$.

It was reported that the proportion of authorship by investigators from U.S. institutions has declined for critical care research publications from $61 \%$ of all authors in 1990 to $41 \%$ in 1999 [7]. This is in contrast to our findings that the proportion of authorship by investigators from U.S. institutions remained fairly constant in both journals with minor fluctuations. 
Table 2: Number of journal articles from 1995-2000 per journal and for individual countries

\begin{tabular}{lcc}
\hline & Academic Medicine & Medical Education \\
\hline Total & 2207 & 746 \\
\hline $\begin{array}{l}\text { Affiliation not } \\
\text { found }\end{array}$ & $35(1.59 \%)$ & $38(5.09 \%)$ \\
\hline
\end{tabular}

Group I: more USA: 1931 (87.49\%)

UK: $318(42.63 \%)$

than 100

Canada: 160 (7.25\%)

Group 2: 10-100 The Netherlands: $13(0.59 \%)$

Israel: $10(0.45 \%)$

Switzerland: $10(0.45 \%)$

UK: 10 (0.45\%)

Australia: 87 (II.66\%)

USA: 78 (10.46\%)

Canada: 43 (5.76\%)

The Netherlands: 26 (3.49\%)

South Africa: 12 (1.61\%)

New Zealand: 10 (1.34\%)

Sweden: 10 (1.34\%)

Group 3: 5-9 New Zealand: 7 (0.32\%)

Australia: 6 (0.27\%)
Germany: 9 (1.21\%)

Israel: 9 (I.21\%)

UAE: 9 (1.21\%)

Hong Kong: 7 (0.94\%)

Ireland: 7 (0.94\%)

Japan: 7 (0.94\%)

Denmark: $6(0.80 \%)$

Finland: $6(0.80 \%)$

Norway: $6(0.80 \%)$

Spain: $5(0.67 \%)$

$\begin{array}{ll}\text { Group 4: } 2-4 & \text { Germany: } 3(0.14 \%) \\ & \text { Saudi Arabia: } 3(0.14 \%) \\ & \text { Brazil: } 2(0.09 \%) \\ & \text { Italy: } 2(0.09 \%) \\ & \text { Singapore: } 2(0.09 \%) \\ & \text { Spain: } 2(0.09 \%) \\ & \text { Thailand: } 2(0.09 \%)\end{array}$

Belgium: 4 (0.54\%)

Egypt: 4 (0.54\%)

Austria: $3(0.40 \%)$

Iran: $3(0.40 \%)$

Lebanon: $3(0.40 \%)$

Bahrain: 2 (0.27\%)

Brazil: 2 (0.27\%)

Hungary: $2(0.27 \%)$

Jordan: $2(0.27 \%)$

Kuwait: $2(0.27 \%)$

Malaysia: $2(0.27 \%)$

Mexico: 2 (0.27\%)

Pakistan: 2 (0.27\%)

Portugal: 2 (0.27\%)

Slovenia: $2(0.27 \%)$

Switzerland: 2 (0.27\%)
Group 5: I
China: I $(0.13 \%)$

Colombia: I (0.13\%)

France: I $(0.13 \%)$

India: I (0.13\%)

Italy: I $(0.13 \%)$

Nepal: I (0.13\%)

Netherland Antilles: I (0.13\%) 
Table 2: Number of journal articles from 1995-2000 per journal and for individual countries (Continued)

$\begin{array}{ll}\text { Sudan: I (0.05\%) } & \text { Nigeria: I (0.13\%) } \\ \text { Sweden: I (0.05\%) } & \text { Saudi Arabia: I (0.13\%) } \\ \text { Turkey: I (0.05\%) } & \text { Singapore: I (0.13\%) } \\ & \text { South Korea: I }(0.13 \%) \\ & \text { Sudan: I (0.13\%) } \\ & \text { Syria: I }(0.13 \%) \\ & \text { Thailand: I (0.13\%) } \\ & \text { Trinidad: I }(0.13 \%) \\ \text { Turkey: I }(0.13 \%)\end{array}$

The countries are separated in five groups according to the number of their publications in each journal in the period from 1995-2000. The percentage is given in brackets. The sum of all numbers may differ from the total number of articles, because some articles had authors from more than one country, and each country was rewarded with a count.

Our search method differed from the previously described method $[1,2]$ of using the "Affiliation field" to enter country names for good reason. First, it was noted that spelling mistakes occur in Medline [19]. These could have an influence if the "Affiliation Field" would have been used to enter country names. When we look at the search strategy used in our study it seems unlikely that the results could have been affected by misspelling. The use of the "Affiliation field" is also limited by the fact, that the name of a country can be dropped from the affiliation if the publisher is located in the same country [20]. Further such a search strategy would be questionable because country names can appear in street names of other countries [20]. Therefore the use of the "Affiliation Field" was avoided right at the beginning and the affiliation for each single entry was retrieved from the MEDLINE format.

This study is limited by the fact that the affiliation in PubMed only includes the institutional affiliation and address of the first author [11]. Therefore some articles may have authors from more than one country, but only the country of the leading author was detected with the applied search strategy. To our surprise a few entries had two countries listed in their affiliation field. Hence some of the articles resulting from international cooperation were found. Besides it seems unlikely that this limitation had a significant influence on the results of this study when we consider the nature of most journal articles dealing with the topic of medical education.

Further we have to remind us that publications about medical education are not only found in journals dedicated to this field, but also in other journals, e.g. general and internal medicine journals. Also contributions about the education in special fields can regularly be found in specialty journals, for example articles about the teaching of anatomy in the Journal of Anatomy. Moreover some countries have journals of medical education in their own language, e.g. the German "Medizinische Ausbildung", which are often not indexed in Medline and are not eval- uated for their impact factor by the Institute of Scientific Information. Some journals are included in other international databases but not in Medline. Furthermore it should be emphasized that many research papers originating from developing world countries and from nonEnglish speaking countries are published in reputable peer-reviewed local or regional journals that are not listed in Medline. What makes things worse is that the already low representation of these journals in Medline is further vanishing, e.g. it is known that there is a progressive disappearance of Latin American journals from Medline [4]. On the other hand researchers striving for the broadest possible exposure and recognition of their work generally prefer to publish their findings in highly cited, international journals [5]. For biomedical disciplines these "highly cited, international" journals are probably those which are covered by Medline [5].

As emphasized by its editor [21], Medical Education is the official journal of the World Federation for Medical Education and has therefore an important international role. In contrast, Academic Medicine is the official journal of the Association of American Medical Colleges. Hence the organizations represented by both journals could explain the difference in the number of contributing countries and the domination of Academic Medicine by North American authors, especially when remembering that journals which represent a national society tend to publish to a certain extent more papers coming from the country of origin of the journal itself than from elsewhere [9].

British authors were the main contributors to the UKbased Medical Education. This is in accordance with previous results from the field of gastroenterology and hepatology showing that a large proportion of papers originating from the UK appeared in British journals [9]. The reasons for this observation remain to be elucidated. One could argue, that a journal is more likely to accept manuscripts submitted from within the country of its own 
origin. But as stated before [9] the 'equal opportunity' policy and the scientific rigor of these journals can't be questioned. Further there is data from a major British medical journal showing that the acceptance rate for submitted manuscripts from the different parts of the world was approximately the same, while the number of submissions from the UK was around fifteen times as high as the numbers from Africa, Asia, South and Central America combined [22]. Accordingly a lower number of submissions from the developing world could be a reason for the geographical distribution in the two investigated journals. On the other hand, an investigation assessing if US reviewers/ non-US reviewers evaluated manuscripts differently, depending on whether the manuscripts were submitted from outside the USA or from the USA, showed that reviewers from the USA and outside the USA evaluated nonUS papers similarly and evaluated papers submitted by US authors more favorably, with US reviewers having a significant preference for US papers [23]. This would indicate that a selection bias must not be ruled out. In the case of Academic Medicine and Medical Education we can only speculate, because the 'native' versus 'foreign' manuscript submission/acceptance rates of these two journals are not known to us. Further we do not know the quality of the submitted manuscripts. The only information available is that Medical Education published around 29\% of unsolicited papers in 2000 [24].

In a recent survey investigators in the less developed world were asked what complicated publication in US or European based journals [25]. They repeatedly referred to the same topics. English as a language barrier constitutes a huge problem [25]. Further the capability of selecting the right journal has an influence. It was stated that some researchers were unfamiliar with the range of journals open to them [25]. Therefore manuscripts that are not accepted for publication in one of the internationally known general medical journals like the BMJ or JAMA, are frequently send to local periodicals while overlooking the speciality journals [25]. In the case of medical education this would suggest that papers are only send to general medical journals while researchers are not aware of the speciality journals in this field like Academic Medicine. But we have to be cautious with this argument, because some researchers deliberately publish their work in the local journals to reach the audience in their home country. If they would publish their paper in an international journal, it could happen that their results never reach the majority of medical professionals in their home country for the same reasons like the language barrier and also scarce library resources. Some journals have supplied evidence against the perception of an editorial bias against work submitted from the developing world. But there seems to be something true about the argument that to secure the maximum number of subscribers who can afford to pay an annual subscription, as well as increasingly discriminating advertisers, journals always have to work hard to appeal to the developed world audience [25]. Therefore the filling of scarce pages with research from the developing world makes no commercial sense and publishers are unlikely to support editors who take their journals in such a direction [25]. This hindrance should be swept away by the appearance of e-journals like the BioMed Central periodicals, which theoretically have no page limitations.

Providing free access to journals for the poorer countries in the world [26] may help to solve some of the other problems. For example developing world researchers, which are not aware of the variety of journals open to their research, have now a possibility to inform themselves. The opportunity of submitting a manuscript via the Internet excludes possible obstacles caused by poor postal services. Further journals should try to remove remaining doubts about their manuscript selection process. This could be achieved by publishing the acceptance and submission rates for each region of the world. The inclusion of more investigators from the developing world on the editorial boards should also be considered [25]. Additionally, researchers from the developing world should be encouraged to submit more of their research to the leading international medical journals.

\section{Conclusions}

The geographical distribution of publications in the two leading medical education journals was investigated. Authors from all over the world published articles in Medical Education and to a lesser extent in Academic Medicine. But while there is a wide distribution of the contributing countries, both journals are dominated by authors from a few English-speaking countries with the exception of the Netherlands.

This study is to the best of our knowledge the first that provides some facts for a discussion about the engagement of single countries on the topic of medical education measured by the amount of their contribution to these two journals.

\section{Competing interests}

None declared

\section{Authors' contributions}

OT designed and carried out the study. He performed the analysis and interpretation of the data and wrote this article.

\section{References}

I. Hefler L, Tempfer C, Kainz C: Geography of biomedical publications in the European Union, 1990-1998. Lancet 1999, 353: I 856

2. Thompson DF: Geography of U.S. biomedical publications, 1990 to 1997. N Engl J Med 1999, 340:817-818 
3. Deleu D, Northway MG, Hanssens Y: Geographical distribution of biomedical publications from the Gulf Corporation Council countries. Saudi Med J 200I, 22: I0-12

4. Rosselli D: Latin American biomedical publications: the case of Colombia in Medline. Med Educ 1998, 32:274-277

5. Lee CS: Productivity of SCI Korean medical papers: 19961997. Korean Med Sci 1999, 14:35I-358

6. Güllüoğlu BM, Aktan AÖ: Scientific publications at a Turkish medical school. Acad Med 2000, 75:760

7. Powner DJ, Kellum JA: Declining critical care research publications by authors from U.S. Institutions, 1990-1999. Acad Med 200I, 76:|26|-1263

8. Weisinger JR, Bellorin-Font E: Latin American Nephrology: Scientific production and impact of the publications. Kidney Int 1999, 56:1584-1590

9. Sorrentino D, De Biase F, Trevisi A, Bartoli E: Scientific publications in gastroenterology and hepatology in Western Europe, USA and Japan in the years 1992-1996: a global survey. Digestion 2000, $61: 77-83$

10. Maleck WH, Boldt J, Koetter KP: Deutsche Publikationen in führenden englischsprachigen Zeitschriften. Dtsch Med Wochenschr 200I, |26:33-41

II. NLM's PUBMed Medline Retrieval System [resource on the World Wide Web]. 200I [http://www.ncbi.nlm.nih.gov/PubMed]

12. 1999 Journal Citation Reports on microfiche - Science edition. Philadelphia, ISI 2001

13. LOCATORplus 2000 [resource on the World Wide Web]. 2002 [http://locatorplus.gov]

14. Berk PD: HEPATOLOGY and hepatology: The good, the bad, and the ugly. Hepatology 1996, 24:1530-1532

15. Kassirer JP: My years at the journal - so far. N Engl ] Med 1995, 333:654-655

16. Opthof T: Sense and nonsense about the impact factor. Cardiovasc Res 1997, 33: I-7

17. NLM's PUBMed Medline Retrieval System [resource on the World Wide Web]. 200 I [http://www.ncbi.nlm.nih.gov/entrez/ query/static/help/pmhelp.html\#PublicationTypes]

18. Kremer JA, Braat DD, Evers JL: Geographical distribution of publications in Human Reproduction and Fertility and Sterility in the 1990s. Hum Reprod 2000, I5:1653-1656

19. Ray JG, Vermeulen MJ: Mizspellin and Medline. BMJ 1996, 313:1658-1659

20. Takei N: Geography of biomedical publications. Lancet 1999, 354:5 16-5 I7

21. Bligh J: From the new editor: continuity and change. Med Educ 1998, 32:229-230

22. BMJ data. $B M] 1998,316: 1519-1520$

23. Link AM: US and non-US submissions. JAMA 1998, 280:246-247

24. Bligh J: Developing the journal. Med Educ 2000, 34:884-885

25. Horton R: North and south: bridging the information gap. Lancet 2000, 355:223I-2236

26. Smith R, Williamson A: BMJ journals free to the developing world. $B M J$ 2002, 324:380

\section{Pre-publication history}

The pre-publication history for this paper can be accessed here:

http://www.biomedcentral.com/1472-6920/2/3/prepub

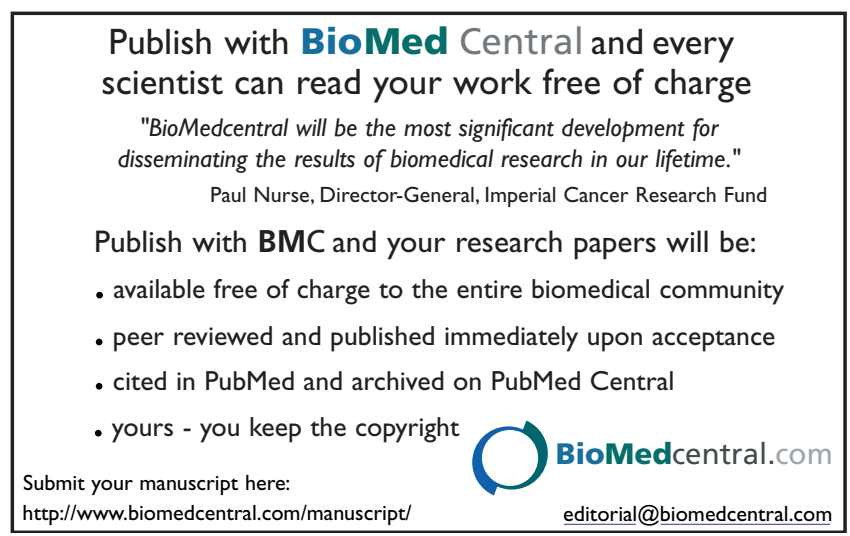

